\title{
PEMBENTUKAN NORMA AMBANG BATAS PARLEMEN DALAM PERSPEKTIF TEORI KRITIS JURGEN HABERMAS
}

\author{
Sholahuddin Al-Fatih ${ }^{1 *}$ \\ 1* Fakultas Hukum, Universitas Muhammadiyah Malang, Indonesia, sholahuddin.alfath@ gmail.com (corresponding).
}

\begin{abstract}
This study tries to discuss the formation of parliamentary threshold norms in the perspective of Jurgen Habermas' critical theory. Through historical, conceptual and statutory approaches, this research attempts to examine prescriptively the dynamics of implementing parliamentary thresholds in legislative elections. This research makes the thinking of Jurgen Habermas and the thinkers around him as a benchmark and analysis. The results of this study indicate that the formation of norms and the application of parliamentary thresholds in elections based on the perspective of Jurgen Habermas's critical theory are appropriate because they do not only look at the legal aspect, but from the needs and interpretations based on other sciences. This research is expected to be able to help academics and legal practitioners, especially regarding electoral law, to be able to dig deeper into the perspective of law and its integration with other disciplines, not only from one or two experts, but from several other experts.
\end{abstract}

Keywords: formation; norm; parliamentary thresholds; Jurgen Habermas

\section{PENDAhUluAN}

Produk legislasi dan hukum dalam suatu negara seringkali tidak bisa dilepaskan dari unsur di luar hukum, seperti kepentingan politik (Habermas, 1992) atau faktor ekonomi.(Posner, 1985) Dalam konteks ke-Indonesia-an, korelasi antara hukum dengan unsur politik maupun ekonomi, sangat erat dan saling melengkapi. Meskipun, dalam banyak kesempatan, kedua unsur di luar hukum tersebut juga sering dianggap merugikan, misalnya dalam pengesahan Undang-Undang Cipta Kerja (Fakultas Hukum Universitas Gadjah Mada, 2020), problematika agraria (Suheri, 2018), penanaman modal asing, pengembangan mobil Timor dan sebagainya.

Unsur di luar hukum terlihat sangat dominan, terutama doktrin mengenai liberalisasi yang muncul dalam beberapa produk legislasi nasional
(Putuhena, 2013). Padahal, liberalisasi bukan merupakan budaya asli bangsa Indonesia, melainkan gagasan yang dibawa dari pemikir barat dengan memuat tiga kredo utama, yaitu: equality atau persamaan, liberty atau kebebasan dan reciprocity atau timbal balik. Ketiga gagasan tersebut, tidak bisa terlepas dari gagasan awal dari para pemikir seperti John Rawls (Rawls, 1999), David A. J. Richards maupun Ronald Dworkin (Nielsen, 1985). Ketiganya dikenal sebagai bapak egalitarian radikal yang melandasi lahirnya liberalisasi modern.

Sayangnya, gagasan tersebut juga masuk ke Indonesia, melalui ide bernama demokrasi (Chambers, 1996). Atas dasar demokrasi yang mencoba meletakkan suara rakyat dan kedaulatan tertinggi berada di tangan rakyat, segala hal terutama faktor ekonomi (Harnay \& Marciano, 2009)(Posner, 1985)(Rustamaji, 2013) dan politik (Wiratraman, 2018), menjadi bagian utama dan 
penting dalam pembentukan sebuah norma hukum. Termasuk di antaranya penentuan besaran dan penerapan norma ambang batas parlemen dalam pemilu. Sebab, melihat dari sejarah penerapan ambang batas parlemen (Al-fatih, Safaat, \& Dahlan, 2014), unsur di luar hukum sangat kental dalam tarik ulur kepentingan, baik berkaitan dengan penentuan besarannya maupun wilayah berlakunya. Dinamika tersebut terus terjadi, sejak ambang batas parlemen pertama kali diperkenalkan dalam pemilu tahun 2004 hingga pemilu tahun 2019 yang lalu (Al-Fatih, 2019)(S. Al Fatih, 2018).

Dinamika yang terjadi tersebut, membuat penerapan ambang batas parlemen juga menciptakan pro dan kontra di tengah masyarakat. Misalnya saja terkait banyaknya partai yang tidak lolos ambang batas parlemen. Dalam pemilu tahun 2019, partai politik yang terdata secara resmi di Kementrian Hukum dan HAM sebanyak 73 partai politik. Namun, dari jumlah tersebut tidak semuanya mendaftar sebagai partai politik peserta pemilu. Hanya terdapat 27 partai politik yang mendaftarkan diri ke Komisi Pemilihan Umum Republik Indonesia. Dari jumlah tersebut yang lolos tahap administrasi dan telah diverifikasi untuk berkontestasi dalam pemilihan umum tahun 2019 hanya sebanyak 16 partai politik nasional, adapun partai yang lolos yakni (Umum, 2020) :

1. Partai Kebangkitan Bangsa (PKB).

2. Partai Gerakan Indonesia Raya (GERINDRA).

3. Partai Demokrasi Indonesia Perjuangan (PDI P).

4. Partai Golongan Karya (GOLKAR).

5. Partai Nasional Demokrat (NASDEM).

6. Partai Gerakan Indonesia Perubahan (GARUDA).

7. Partai Berkarya (BERKARYA).

8. Partai Keadilan Sejahtra (PKS).

9. Partai Persatuan Indonesia (PERINDO).

10. Partai Persatuan Pembangunan (PPP).

11. Partai Solidaritas Indonesia (PSI).

12. Partai Amanat Nasional (PAN).

13. Partai Hati Nurani Rakyat (HANURA).

14. Partai Demokrat (DEMOKRAT).

15. Partai Bulan Bintang (PBB).
16. Partai Keadilan dan Persatuan Indonesia (PKP I).

Dari 16 partai politik peserta pemilu tersebut, hanya ada 9 partai politik yang berhasil melewati ambang batas parlemen. Berikut perolehan suara partai-partai pada Pemilu Legislatif 2019 yang telah ditetapkan oleh KPU, diurutkan berdasarkan suara tertinggi ke terendah (Kompas, 2019) :

1. PDI-P: 27.053 .961 (19,33 persen)

2. Gerindra: 17.594 .839 (12,57 persen)

3. Golkar: 17.229 .789 (12,31 persen)

4. PKB: 13.570 .097 (9,69 persen)

5. Nasdem: $12.661 .792(9,05$ persen $)$

6. PKS: $11.493 .663(8,21$ persen $)$

7. Demokrat: 10.876 .507 (7,77 persen)

8. PAN: $9.572 .623(6,84$ persen $)$

9. PPP: 6.323 .147 (4,52 persen)

10. Perindo: 3.738 .320 (2,67 persen)

11. Berkarya: 2.929 .495 (2,09 persen)

12. PSI: 2.650 .361 (1,89 persen)

13. Hanura: 2.161 .507 (1,54 persen)

14. PBB: 1.099 .848 (0,79 persen)

15. Garuda $702.536(0,50$ persen $)$

16. PKPI 312.775 ( 0,22 persen)

Berdasarkan hasil tersebut, maka ada 7 partai politik peserta pemilu 2019 yang gagal lolos ke parlemen karena tidak bisa melewati besaran ambang batas parlemen. Perindo, Berkarya, PSI, Hanura, PBB, Garuda dan PKPI yang gagal melewati ambang batas parlemen, otomatis suaranya terbuang dan tidak diikutkan dalam perhitungan kursi parlemen. Suara mereka akan masuk dalam suara sisa yang diperebutkan oleh partai politik yang lolos parlemen. Praktik kanibalisme suara dalam penerapan ambang batas parlemen ini, secara nyata bisa menderogasi hak sipil dan politik warga negara.

Berdasarkan latar belakang tersebut, penulis mencoba menganalisis tentang pembentukan norma dan penerapan ambang batas parlemen dalam pemilu di Indonesia menurut perspektif teori kritis Jurgen Habermas (Tjahyadi, 2003). Penulis mencoba melihat sejarah diterapkannya ambang batas parlemen dalam pemilu, hingga menggali fakta maupun data terkait dengan pro dan kontra atas pembentukan norma ambang batas parlemen tersebut. Melalui penelitian ini, penulis 
berharap bisa menemukan relasi antara pembentukan norma ambang batas parlemen dan pemikiran kritis Jurgen Habermas, gagasan yang melihat hukum dari beragam aspek dan bukan dari sisi hukum semata. Penelitian ini diharapkan memberikan kontribusi dalam bidang hukum, khususnya kajian mengenai filsafat hukum yang semoga mampu memberikan penemuan untuk kemajuan di bidang keilmuan hukum dan membantu para akademisi maupun praktisi dalam menerapkan ambang batas parlemen di masa yang akan datang.

\section{METODE PENELITIAN}

Penelitian ini adalah jenis penelitian hukum dengan pendekatan konseptual (conceptual approach) dan pendekatan perundang-undangan (statuta approach).(Peter Mahmud Marzuki, 2014) Penelitian hukum merupakan suatu penelitian yang mengkaji norma, berkaitan dengan tumpang tindih, kekosongan maupun kekaburan norma yang ada. Norma yang coba dikaji dalam penelitian ini adalah berkaitan dengan norma ambang batas parlemen atau parliamentary threshold. Konsep yang dijadikan sebagai alat ukur adalah gagasan tentang teori kritis Jurgen Habermas, sementara peraturan perundangundangan yang digunakan dalam penelitian ini adalah Undang-Undang tentang Pemilu. Melalui analisis preskriptif (Peter Mahmud Marzuki, 2017), penulis mencoba menemukan argumentasi baru berkaitan dengan ambang batas parlemen dalam perspektif Jurgen Habermas.

Sebagaiaman telah disebutkan sebelumnya, penelitian ini menggunakan 2 (dua) model pendekatan yang terdiri dari pendekatan undangundang (statute approach) dan pendekatan konseptual (conceptual approach) (Peter Mahmud Marzuki, 2017). Pertama, menggunakan pendekatan undang-undang (statute approach), pendekatan ini diterapkan karena akan meneliti norma hukum tentang ambang batas parlemen atau parliamentary threshold yang terdapat dalam Undang-Undang Pemilu (Undang-Undang Nomor 7 Tahun 2017 sebagai UU Pemilu terakhir), dan peraturan perundang-undangan atau Putusan Mahkamah Konstitusi yang terkait dengan ambang batas parlemen tersebut.
Kedua, pendekatan konseptual (conceptual approach), karena penelitian ini nantinya akan dimulai dengan melakukan identifikasi terhadap prinsip-prinsip atau pandangan doktrin yang sudah ada untuk kemudian memunculkan gagasan baru. Konsep yang dijadikan sebagai pisau analisis dalam penelitian ini adalah konsep tentang Teori Kritis yang disampaikan oleh Jurgen Habermas. Tak hanya itu, gagasan tokoh atau pakar disekitar Jurgen Habermas juga menjadi salah satu batu uji untuk mengukur gagasan Jurgen Habermas itu sendiri. Kemudian, gagasan Jurgen Habermas idgunakan untuk menilai norma hukum tentang ambang batas parlemen dan pembentukannya di Indonesia.

Adapun sumber bahan hukum yang diperoleh dalam penelitian ini yaitu bahan hukum utama atau primer, bahan hukum tambahan atau sekunder dan bahan hukum yang bersifat tersier. Ketiga bahan hukum tersebut dapat dijelaskan sebagai berikut:

a) Bahan Hukum Primer

Bahan-bahan hukum primer memiliki sifat otoritatif, yang artinya memiliki otoritas. Bahan-bahan hukum primer dalam hal ini terdiri dari peraturan perundang-undangan, catatan-catatan yang resmi maupun suatu risalah dalam pembuatan peraturan perundang - undangan.

b) Bahan Hukum Sekunder

Bahan hukum sekunder merupakan bahan hukum yang bersifat membantu atau menunjang bahan hukum primer dalam penelitian yang akan memperkuat penjelasan didalamnya. Bahan hukum sekunder merupakan semua publikasi tentang hukum, yang bukan merupakan dokumen resmi, yang meliputi literatur-literatur, hasil penelitian, buku-buku teks, jurnal-jurnal hukum, makalah, komentar-komentar atas putusan pengadilan, kamus hukum, dan ensiklopedia yang dapat diakses melalui media internet berkaitan dengan permasalahan yang dibahas dalam penulisan penelitian ini, dan juga bahanbahan hukum lainnya yang terkait dengan permasalahan penelitian.

c) Bahan Hukum Tersier

Selain bahan hukum primer dan sekunder, peneliti akan menggunakan bahan hukum 
berupa bahan hukum tersier yang berupa bahan non-hukum tetapi apabila memang dianggap perlu.

Teknik yang digunakan dalam pengumpulan bahan hukum pada penelitian ini adalah dengan melakukan "library research". Teknik library reseach adalah teknik pengumpulan bahan hukum dengan melakukan studi kepustakaan yang memiliki keterkaitan dengan objek kajian permasalahan yang akan diteliti. Fungsi dari teknik memperoleh data ini dalam penelitian adalah untuk mencari jawaban dari rumusan masalah dengan mengkaji bahan hukum kepustakaan yang relevan atau berkaitan dengan permasalahan.

Untuk mendapatkan bahan-bahan yang dibutuhkan kaitannya dengan masalah yang diteliti, oleh karena itu teknik yang digunakan dalam penelusuran bahan hukum yang akan digunakan dalam penelitian ini adalah melalui studi pustaka atau (library research), dengan beberapa cara, yaitu :

a) Mengumpulkan bahan hukum primer yaitu melalui studi kepustakaan, serta juga mengumpulkan semua informasi yang bekaitan dengan bahan hukum primer.

b) Mengumpulkan bahan hukum sekunder yaitu melalui berbagai literatur dan beberapa informasi yang dapat menunjang sehingga dapat membantu kaitannya dengan bahan hukum sekunder yang mempunyai hubungan keterkaitan dengan masalah yang diteliti oleh penulis.

c) Mengumpulkan bahan hukum tersier yaitu dengan melakukan wawancara dengan pihak-pihak berkompeten dari instansi terkait dan melakukan penelusuran internet.

\section{HASIL DAN PEMBAHASAN}

\section{Biografi Singkat Jurgen Habermas (Yazid,} 2009)

Jurgen Habermas lahir di kota Dusseldorf, Jerman pada tanggal 18 Juni 1929. Negara kelahirannya, Jerman, telah melahirkan sejumlah filsuf besar dan berpengaruh pada zamannya, di antaranya adalah, Immanuel Kant (1724-1804), Arthur Shopenhauer (1788-1860), Johann
Wolfgang von Goethe (1749-1832), Johann Gottlieb Fichte (1762-1814), Friedrich Schelling (1775-1854), George Wilhelm Friedrich Hegel (1770-1831), Karl Marx (1818-1883), Friedrich Nietzsche (1844-1900), Wilhelm Dilthey (18331911), Edmund Husserl (1859-1938), Max Scheler (1874-1928), Karl Jaspers (1883-1969), Martin Heidegger (1889-1976), Max Horkheimer (1895-1973), Theodor Wiesengrund Adorno (1903-1969), dan Herbert Marcuse (1898-1979, dan tentunya masih banyak lagi (M. K. Fatih, 2020). Dari deretan nama-nama pemikir di atas, banyak yang telah mempengaruhi pemikiran Jurgen Habermas, diantaranya adalah Immanuel Kant, Hegel, karl Marx, dan tentunya Mazhab Frankfurt generasi pertama, seperti Adorno dan Horkheimer (M. K. Fatih, 2020).

Jurgen Habermas belajar di Universitas Gottigen dengan fokus studi sastra Jerman, filsafat dan ikut serta dalam kuliah-kuliah ekonomi dan psikologi. Di Universitas Bonn Jurgen Habermas juga belajar filsafat. Pada tahun 1954 Jurgen Habermas meraih gelar doktor filsafat pada usia 27 tahun (Hardiman, 2009). Setelah lulus, Jurgen Habermas bergabung dengan Mazhab Frankfurt dan menjadi asisten Adorno pada tahun 1956. Jurgen Habermas menjabat sebagai profesor filsafat di Universitas J. Von Goethe, Frankfurt pada tahun 1964 (Lubis, 2015). Jurgen Habermas bukan dikenal sebagai pemikir yang memprioritaskan pada hermeneutik, tetapi lebih dikenal sebagai seorang teoretikus sosial dan filsuf terkemuka di Jerman.

Sebagai peneliti dan juga akademisi, Jurgen Habermas menjalankan dua peran ganda yang ia lakukan di Jerman. Sebagai seorang teoritikus sosial, Jurgen Habermas memfokuskan pada problem komunikasi intersubjektif. Teori komunikasi intersubjektif ini muncul karena beberapa pengalaman pribadinya. Pada masa kecilnya, Jurgen Habermas memiliki dua pengalaman yang sangat kuat melekat dalam memorinya. Pertama, akibat serangkaian operasi atas bibir sumbingnya yang menajamkan kesadarannya bahwa ia memiliki pengalaman traumatis tentang kesalingtergantungan antar manusia. Kedua, saat pertama masuk sekolah ia kerap diejek teman-temannya karena sulitnya 
dalam hal berkomunikasi, dikarenakan bibir sumbingnya yang berdampak langsung pada proses pengucapan lisan. Dengan latar belakang ini, maka habermas lebih percaya akan keunggulan bahasa tertulis dari pada lisan (Hardiman, 2015).

Selanjutnya, pemikiran Jurgen Habermas sangat dipengaruhi oleh para filsuf sebelumnya. Pengaruh terhadap pemikiran Habermas ini sudah terlihat sejak dari para pemikir pragmatisme. Para tokoh pragmatis ini mulai muncul sejak masa Habermas pada tahun 1960-an, salah satu gurunya yang mempengaruhi dirinya adalah Karl Otto Apel, yang memintanya untuk mempelajari karya-karya para tokoh pragmatisme Amerika, seperti John Dewey, James, dan Pierce.

Dari pengaruh filsuf penganut pragtisisme tersebut, Jurgen Habermas menciptakan beberapa gagasan, diantaranya: "komunikasi bebas paksaan", "pembentukan konsesus" atau "komunikasi intersubjektif". Pemikiran Jurgen Habermas juga sangat di pengaruhi oleh beberapa tokoh, seperti Max Weber, Austin atau juga Wittgenstein II. Misalnya pemikiran dari Max Weber, Habermas meminjam konsep "diferensiasi nilai", sedangkan dari Austin dan Wittgenstein II, Habermas banyak dipengaruhi oleh teori "bahasa". Selain pemikiran dari tokoh-tokoh tersebut, pemikiran Habermas juga dipengaruhi oleh pemikiran Kohlberg dan Piaget. Dari kedua tokoh ini, Habermas cenderung mengambil konsep tentang "perkembangan moral". Habermas mempunyai suatu komitmen yang dapat dilhat dari sebuah karyanya. Dalam karya tersebut berisi komitmen terhadap keadilan sosial, dukungan atas kesetaraan sosial, pemeliharaan kepentingan umum, dan komitmennya yang tinggi atas pelaksanaan demokrasi (Lubis, 2015).

Dua peristiwa besar yaitu Perang Dunia II dan hidup dibawah tekanan rezim nasional-sosialis Adolf Hitler menjadi pengalaman pahit yang ia rasakan sewaktu remaja, yang kemudian mengantarkannya untuk memberikan penjelasan tentang pentingnya demokrasi melalui pemikiran politiknya. Jurgen Habermas merupakan seorang filsuf yang begitu kritis terhadap pemikiran Marxis, bukan hanya Marxismeortodoks, melainkan juga neo-Marxisme. Ia berusaha menyesuaikan warisan Marx dengan tuntutan yang berkembang pada zamannya, sehingga yang dilakukannya tidak hanya mencoba mengupas kembali karya-karya Marx sebagai bahan analisisnya, melainkan juga menafsirkan kembali karya-karya yang telah ditafsirkan oleh para pemikir dan pengikut Marxis (Yazid, 2009).

Bahkan, ia tidak segan-segan mengkritik habis pemikiran Marx yang tercantum dalam teori kritik ideologinya. Selain menulis karya penting dalam filsafat dan ilmu-ilmu sosial kemanusiaan yang sangat produktif, Jurgen Habermas juga melakukan banyak perdebatan penting dalam filsafat dengan beberapa tokoh, seperti dengan Gadamer, Niklas Luhmann, Jacques Derrida, Michel Foucault, Kardinal Ratzinger. Pemikiran Jurgen Habermas secara langsung atau tidak langsung dibahas di dalam teologi, karena dalam beberapa kesempatan, Jurgen Habermas melakukan diskusi dengan beberapa teolog Kristiani. Beberapa teolog tersebut antara lain Edward Schillebeeckx, Helmut Peukert, dan Michael Theunissen (Yazid, 2009).

Boleh dikatakan, Habermas adalah contoh seorang filsuf yang mengembangkan teorinya langkah demi langkah dalam perdebatan dengan para teoretikus lain. Di tahun 80-an ia memusatkan perhatiannya pada etika diskursus dan dengan minatnya pada filsafat politik John Rawls (Rawls, 1999) ia mengembangkan teori demokrasi deliberatif (Malik, 2019) dalam karyanya Faktizitat Und Geltum.

Demokrasi deliberatif menurut Jurgen Habermas ialah model demokrasi yang menekankan prosedur deliberasi dalam melegitimasi serta menentukan keputusan atau kebijakan. Proses deliberasi berada di ruang publik yang ruang publik tersebut bernaung dalam lapisan masyarakat Lifeworld dimana lapisan masyarakat tersebut menjunjung rasionalitas komunikatif bukan rasionalitas instrumental seperti lapisan masyarakat yang berada di dalam sistem (Malik, 2019).

Secara umum dalam gambaran karyanya, orang akan mengatakan bahwa Jurgen Habermas memulai karirnya sebagai seorang Marxis tetapi mengakhirinya sebagai pembela demokrasi liberal. Karikatur dan gambaran umum tersebut tidak sepenuhya benar, karena dia bersikap kritis 
atas Marxisme dan juga atas liberalisme Amerika. Setelah pensiun dari kedudukannya di Frankfurt, Jurgen Habermas tinggal di Starnberg dan masih aktif menulis komentar-komentar politis. Ia menulis berbagai topik, seperti tentang rekayasa genetis, terorisme, penyatuan kembali Jerman, kosmopolitanisme, dan juga tentang masyarakat pasca sekuler. Habermas adalah salah seorang filsuf Jerman yang karyanya masih hidup. (Hardiman, 2015).

Habermas mempunyai banyak karya yang telah ditulisnya. Boleh dikatakan bahwa seluruh karyanya dari tahun 1950-an hingga tahun 1970-an merupakan persiapan dan latihan untuk menemukan posisi epistemologisnya. Salah satu bukunya yaitu, Knowledge and Human Intersts, yang dipublikasikan pada tahun 1968, yang membahas terkait pengetahuan manusia yang dihasilkan oleh kepentingan kognitif manusia. Kemudian, The Theory of Communicative Action, merupakan buku dua jilid yang menjadi magnum opusnya, dan buku tersebut dipublikasikan pada tahun 1981 dan 1983. Buku tersebut adalah gambaran dari posisi epistemologis-nya. Karya-karyanya yang datang setelah buku itu merupakan ulasan penjelas, kecuali buku Between facts and Norms, yang merupakan penerapan epistemologinya ke bidang politik (M. K. Fatih, 2020).

\section{Teori Kritis Jurgen Habermas dalam Memandang Pembentukan Norma Ambang Batas Parlemen}

Menurut Jurgen Habermas, teori kritis bukanlah teori ilmiah, yang biasa dikenal dikalangan publik akademis dalam masyarakat kita. Jurgen Habermas menggambarkan Teori kritis sebagai suatu metodologi yang berdiri di dalam ketegangan dialektis antara filsafat dan ilmu pengetahuan (sosiologi). Teori Kritis tidak hanya berhenti pada fakta-fakta objektif, yang umumnya dianut oleh aliran positivistik. Teori krtis berusaha menembus realitas sosial sebagai fakta sosiologis, untuk menemukan kondisi yang bersifat trasendental yang melampaui data empiris (M. K. Fatih, 2020).
Dapat dikatakan, Teori kritis merupakan kritik ideologi. Teori kitis ini dilahirkan oleh Mazhab Frankfurt yang bermaksud untuk membuka seluruh selubung ideologis dan irasionalisme yang telah melenyapkan kebebasan dan kejernihan berpikir manusia modern. Akan tetapi, semua itu konsep Teori Kritis yang ditawarkan oleh para pendahulu Jurgen Habermas (Max Horkheimer, Theodor Adorno, dan Herbert Marcuse) mengalami sebuah kemacetan atau berakhir dengan kepesimisan. Akan tetapi, teori ini tidak berakhir begitu saja, Jurgen Habermas sebagai penerus Mazhab Frankfurt akan membangkitkan kembali teori tersebut dengan sebuah paradigma baru (M. K. Fatih, 2020).

Teori kritis menurut Habermas disebut dengan "teori dengan maksud praktis" berarti tindakan yang membebaskan model teori kritis dengan maksud praktis. Teori kritis mencoba melihat adanya perubahan dalam kehidupan sosial. Namun perubahan tersebut tetap dalam kerangka sosial yang nyata (Borradori, 2005) Teori Kritis bekerja atas dasar suatu kerangka metateoritis (Miller, 2002). Teori Kritis berpijak pada suatu pandangan umum tentang hakikat realitas sosial, baik dalam dimensi faktual maupun dimensi normatif. Belajar dan mengamati realitas-realitas sosial masa lalu dan realitas sosial masa kini perupakan pijakan penting dalam membangun proyeksi masyarakat yang diharapkan. Suatu ontologi sosial selalu berdimensi historis-faktual dan sekaligus proyektif (Tjahyadi, 2003).

Suatu pandangan umum tentang hakikat masyarakat akan membentuk cara pandang terhadap masa lalu dan masa kini, namun sekaligus juga mengarah pada proyeksi masyarakat yang dicita-citakan. Pada pendekatan seperti inilah diusahakan untuk diungkap perspektif ontologi sosial Jurgen Habermas tentang masyarakat modern dan masyarakat kapitalisme lanjut (Tjahyadi, 2003). Jurgen Habermas dalam pemikiran kritisnya seringkali membandingkan antara satu teori dalam hukum dengan teori dari disiplin ilmu yang lain. Misalnya saja, Jurgen Habermas membahas tentang hukum dari sudut pandang moral, etika bahkan berdasarkan disiplin ilmu komunikasi (White, 1988). 
Sholahuddin Al-Fatih.

pp. 24-37
E-ISSN: 2723-2476

ISSN : 2723-1968

ACLJ, Vol. 1, Issue 1, 2020
Jurgen Habermas menyadari, cara memahami hukum melalui sudut pandang yang beragam tersebut bisa saja melahirkan pola berpikir subyektif, namun subyektifitas tersebut justru akan memperkaya khazanah keilmuan hukum itu sendiri. Cara berpikir unik ala Jurgen Habermas inilah yang menarik untuk dijadikan sebagai tolok ukur dalam melihat norma hukum di era modern (Amri, 2008) saat ini, terutama di Indonesia.

Apakah benar kemudian jika hukum di Indonesia sangat bergantung pada sudut disiplin ilmu yang lain (Aulia \& Al-Fatih, 2017). Pertanyaan sederhana tersebut sepertinya tidak bisa dijawab hanya dengan bangunan teori, melainkan juga harus dirumuskan secara kompleks berdasarkan pada praktik berhukum di tengah masyarakat (Suteki \& Taufani, 2018). Termasuk dalam konteks pembentukan norma dan penerapan ambang batas parlemen di Indonesia. Sejarah pembentukan norma ambang batas parlemen menunjukkan bahwa saat itu ambang batas parlemen diterapkan untuk membatasi euforia masyarakat yang ingin membentuk partai politik pasca reformasi (Al-fatih et al., 2014). Sebab, pasca reformasi masyarakat memang cenderung menginginkan kebebasan yang sebebas-bebasnya pasca dikekang dalam orde baru (Effendi, 2017).

Dampaknya, banyak masyarakat yang terobsesi untuk membentuk partai politik. Buktinya, banyak partai yang lolos dan menjadi peserta pemilu. Atas dasar tersebut, pemerintah berupaya mewujudkan sistem multi partai sederhana. Salah satu caranya adalah dengan menerapkan ambang batas parlemen, baik yang dikenal dengan istilah electoral threshold maupun parliamentary threshold (Al-Fatih, 2019). Kondisi dan latar belakang pembentukan norma ambang batas parlemen tersebut sesuai dengan gagasan awal yang disampaikan oleh Imre Lakatos (White, 1988) yang membagi ilmu alam dalam dua obyek, yaitu obyek utama yang mempelajarinya secara langsung dan interpretasi atas obyek utama tersebut. Konsep inilah yang terjadi dalam penerapan ambang batas parlemen di Indonesia (Al-fatih et al., 2014).

Sebab, secara historis sebagaimana telah disebutkan, ambang batas parlemen yang berlaku di Indonesia memang digunakan untuk membatasi partai politik.(Mellaz, 2012) Inilah obyek utama dari ambang batas parlemen. Imre Lakatos menyebutnya sebagai "core concept of a program." Sementara, interpretasi dari penerapan ambang batas parlemen, bisa ditafsirkan secara beragam, baik melalui disiplin ilmu politik, ekonomi dan sebagainya.

Jika dilihat dari sisi politis (Putra, 2019) maka penerapan ambang batas parlemen sejatinya adalah digunakan untuk mempertahankan kekuasaan partai politik besar. Melalui ambang batas parlemen, partai politik parlemen bisa melakukan konsolidasi yang tepat, ideal dan dapat dipertanggungjawabkan (Taufiqulhadi, 2015). Dalam konteks tersebut, ambang batas parlemen memang secara politis terlihat jelas berperan dalam mewujudkan sistem pemerintahan yang kuat, termasuk pula mempertahankan pola oligarki di negara demokrasi (Jati, 2013).

Implementasi norma ambang batas parlemen dalam pemilu di Indonesia merupakan cara untuk menciptakan politik hukum sistem multipartai yang sederhana (jumlah partai politik banyak, tapi hanya ada sedikit partai politik yang bisa ikut terlibat dalam pengambilan keputusan). Khususnya, dalam mewujudkan sistem pemerintahan presidensial murni di Indonesia. Kenaikan ambang batas parlemen dalam pemilu tahun 2019 lalu menjadi 4\% pun bertujuan untuk membangun kehidupan politik dengan menciptakan stabilitas antara sistem kepartaian dengan pemerintahan presidensial dalam suasana mewujudkan check and balances (Hadi \& Brata, 2020).

Secara politis praktis, ambang batas parlemen menjadi salah satu upaya penyederhanaan partai politik dan jika sudah disederhanakan maka sistem presidensial akan kuat dan stabil (Hadi \& Brata, 2020). Hal ini karena jika banyak partai yang lolos ambang batas parlemen maka pada saat pengambilan kebijakan akan berdampak pada stabilitas pemerintahan karena banyaknya partai politik dengan kepentingannya masing-masing (Hadi \& Brata, 2020). Alasan politis tersebut hampir selalu menghiasi dan menjadi faktor utama dalam penentuan besaran ambang batas parlemen di setiap periodisasi pemilu. 
Selain itu, ambang batas parlemen juga diharapkan bisa digunakan untuk mendorong pembangunan partai politik yang lebih sehat, mengingat peran dan fungsi sebuah partai politik telah diatur dengan sangat jelas dan tegas dalam UUD NRI 1945 dan peraturan perundangundangan (Fahmi, 2017). Dengan adanya partai politik yang tidak lolos ambang batas parlemen, maka hal itu bisa mendorong terjadinya reformasi kepartaian, baik dalam internal partai maupun eksternal partai. Partai politik akan bisa memilih, apakah akan mempertahankan eksistensi partai mereka dengan memperkuat kaderisasi dan keanggotaan atau memilih jalur politik praktis dengan berpindah haluan untuk melebur ke dalam partai lain.

Sementara jika dilihat dari faktor ekonomi (Harnay \& Marciano, 2009), ambang batas parlemen dapat menciptakan efisiensi kinerja parlemen dalam mengambil keputusan karena jumlah partai politik parlemen dibatasi. Sebuah praktik parlemen dengan jumlah partai politik sedikit seperti di Jerman, menghasilkan sistem pemerintahan yang relatif stabil dan efektif.(Ilham Fajar Septian, 2019) Kondisi tersebut berbeda dengan di Indonesia, di mana banyak sekali partai politik peserta pemilu, yang sudah dibatasi dengan penerapan ambang batas parlemen, namun masih saja banyak partai politik yang lolos ke parlemen. Dampak dari banyaknya partai politik di parlemen, membuat inefisiensi kinerja parlemen. Sehingga, jika dilihat dari realitas faktor ekonomi, penerapan ambang batas parlemen lebih berfokus pada efisiensi kinerja parlemen jika jumlah partai lolos parlemen hanya sedikit.

Salah satu tokoh yang menyatakan adanya relasi antara hukum dengan faktor ekonomi, termasuk soal efisiensi adalah Richard Posner (Harnay \& Marciano, 2009)(Posner, 1985). Richard Posner dalam perkembangan cara berpikirnya, telah melalui fase pergeseran dari mempelajari hukum dan ekonomi (law and economics) menjadi mempelajari analisis ekonomi dalam hukum (economic analysis of law) (Harnay \& Marciano, 2009). Meskipun penelitian yang dilakukan oleh Posner banyak berfokus pada kriminologi dan hukum pidana serta relasinya dengan faktor ekonomi.

Posner melihat bahwa analisis ekonomi bisa dijadikan sebagai metode untuk menganalisa masalah hukum yang bisa berdampak pada putusan hakim. Penjelasan dari Posner tersebut cukup rasional, mengingat bahwa Posner besar dan berkembang di negara common law yang mendasarkan hukumnya pada putusan pengadilan/hakim (Sianipar, 2019)(Sodiki, 2020)(Simanjuntak, 2018)(Agustine, 2018). Menjadi menarik untuk dibahas adalah apakah gagasan Posner tersebut bisa juga diterapkan di negara civil law atau tidak.

Gagasan Posner tersebut kemudian menjadi topik bahasan yang hangat diperbincangkan oleh para akdemisi hukum, salah satunya dibahas oleh Ch. Himawan (Himawan, 1991). Himawan berpendapat bahwa salah satu cara untuk membangkitkan wibawa hukum di Indonesia adalah dengan menyiramkan air berisikan konsepkonsep ekonomi kepada hukum Indonesia yang sedang tertidur. Sebab, oleh para pakar hukum yang menilai pranata hukum sebagai komoditi (Lolong, 2017), maka mereka akan senantiasa menjaga komoditi tersebut agar tetap berkualitas dengan pembinaan dan pembaharuan. Dengan cara ini, hukum Indonesia bisa menjadi hukum yang bagus, tidak hanya di kawasan ASEAN namun juga Asia dan dunia.

Himawan dalam menyajikan gagasan analisis ekonominya terhadap hukum, mengambil dua konsep sebagai alat ukur, yaitu maksimalisasi dan keseimbangan (Himawan, 1991). Dalam konsep maksimalisasi, pranata hukum dijadikan sebagai alat untuk mencapai target maksimal atas pemecahan permasalahan yang ada. Sementara dalam konsep keseimbangan, mencoba mengendalikan upaya maksimal terhadap pranata hukum yang ada.

Berdasarkan ide maksimalisasi, maka Pemerintah terus berupaya menaikkan angka besaran parliamentary threshold dari 2,5\% menjadi 4\% pada pemilu terakhir tahun 2019 lalu. Hal ini tentu menjadi fenomena dari upaya pemerintah untuk memaksimalkan besaran parliamentary threshold yang ada. Sebab, sejarah 
mencatat, beberapa negara justru menerpakan angka parliamentary threshold yang jauh lebih besar dibandingkan Indonesia. Negara seperti Turki (Mouliza K.D Sweinstani, 2019) dan beberapa negara di Eropa lainnya, menerapkan parliamentary threshold pada batas diluar wajar hingga mencapai $10 \%$.

Selanjutnya pada konsep keseimbangan, pemerintah mencoba mengambil jalan tengah tentang besaran parliamentary threshold tersebut. Jalan tengah yang ditempuh oleh pemerintah nampak pada besaran parliamentary threshold yang terakhir, yakni $4 \%$. Besaran $4 \%$ mengindikaiskan bahwa pemerintah mencoba untuk melakukan penyeimbangan dan persebaran suara di antara kosntituen partai politik peserta pemilu. Mungkin, pemerintah juga belum terlalu berani mengambil resiko untuk disebut sebagai perampok suara rakyat. Sebab, selama ini suara partai politik yang gagal memenuhi parliamentary threshold menjadi suara sisa yang kursinya dikonversikan untuk partai politik yang lolos parliamentary threshold.

Sehingga, perspektif ekonomi dan relasinya dengan hukum, sepertinya akan bertolak belakang dari perspektif Hak Asasi Manusia. Sebab, sudut pandang yang bertolak belakang akan muncul dari perspektif Hak Asasi Manusia (Jati, 2013). Penerapan ambang batas parlemen dengan besaran 2,5\% sampai $4 \%$ dalam sejarah pemilu Indonesia, membuat hak memilih dan dipilih jadi terbatas.

Keadaan ini tentunya tidak sejalan dengan prinsip HAM, termasuk yang tertuang dalam International Covenant on Civil and Political Rights (ICCPR). Melalui penerapan ambang batas parlemen, ada suara pemilih yang terbuang karena gagal melewati besaran ambang batas parlemen (Adelina, 2018). Beberapa partai secara nyata menjadi korban dari penerapan ambang batas parlemen ini, seperti PBB, PKPI, PPP, Perindo, PSI, PDS dan banyak lagi (Kompas, 2019). Suara yang diperoleh oleh partai-partai tersebut dari konstituen mereka, terbuang dan tidak mendapatkan legitimasi hanya karena suara partai secara nasional gagal melewati besaran ambang batas parlemen (Faiz, 2018).

Kegagalan partai politik dan terbuangnya suara masyarakat akibat penerapan ambang batas parlemen, tentu bertentangan dengan Pasal $28 \mathrm{C}$ ayat (2) UUD NRI Tahun 1945, berkaitan dengan hak politik. Adanya kerugian hak politik yang dijamin oleh Konstitusi (Putri, 2018), tentu bisa menjadi topik yang menarik untuk diperdebatkan dalam ruang akademik. Kerugian konstitusional tersebut (Pamungkas, 2014), walaupun oleh Mahkamah Konstitusi tidak dianggap inkonstitusional, tentu masih bisa dikaji ulang. Lebih lanjut, kerugian yang dialami peserta dan pemilih pada Pemilu akibat adanya ambang batas parlemen bukan hanya satu kerugian melainkan lebih dari satu.

Kerugian bagi peserta Pemilu adalah parpol yang tidak melewati ambang batas parlemen, yaitu (Kholis, 2020): (1) tidak dapat memunculkan aspirasi konstituen yang telah memilihnya dan (2) hilangnya suara konstituen yang memilih. Kedua kerugian ini merupakan hak politik partai politik. Penyerapan dan aspirasi masyarakat merupakan hak partai politik sebagai penyangga demokrasi. Soal hilangnya suara partai politik jelas merupakan hilangnya hak politik partai politik. Partai politik berhak mendapatkan suara dari publik dan tidak boleh ada instrumen yang bisa menghilangkan suara. Mengingat pemungutan suara merupakan hak politik yang paling dasar bagi semua manusia (Kholis, 2020).

Kemudian kerugian pemilih di Pemilu. Masyarakat sebagai pemilih yang memiliki hak pilih jelas dirugikan dengan adanya ambang batas parlemen. Orang yang dirugikan dengan adanya ambang batas parlemen adalah orang yang memilih partai politik dan/atau calon anggota legislatif tetapi tidak lolos karena adanya ambang batas parlemen (Kholis, 2020). Kerugian yang diperoleh masyarakat dengan adanya hal-hal seperti (Kholis, 2020): (1) Hilangnya suara rakyat secara sia-sia dan percuma karena bagi pemilih yang memilih partai politik dengan perolehan di bawah ambang batas parlemen (Maftuh, 2020); (2) pemilih tidak dapat menyalurkan aspirasinya di parlemen sesuai dengan keinginannya berdasarkan program partai politik karena terkendala ambang batas parlemen (Ansori, 2019); (3) masyarakat dirugikan karena tidak bisa menempatkan calon anggota legislatif di DPR. Bahkan jika suara calon legislatif terpilih sama dengan salah satu kursi atau 
seharga dengan satu kursi di parlemen. Namun karena adanya ambang batas parlementer, partai politik tidak lolos, sehingga otomatis calon anggota legislatif dari partai politik tersebut juga tidak lolos (Kholis, 2020).

Sehingga, berdasarkan sudut pandang HAM, maka pembentukan norma ambang batas parlemen di Indonesia, sangat tidak sesuai dengan konstitusi, terutama Pasal $28 \mathrm{C}$ ayat (2) UUD NRI Tahun 1945, berkaitan dengan hak politik. Keragaman sudut pandnag atas sebuah norma hukum, merupakan hal yang wajar jika ditinjau dari perspektif teori kritis Jurgen Habermas. Sebab Jurgen Habermas memang tidak secara mutlak melihat suatu hukum, bahkan sebuah pranata sosial, hanya dari satu sudut pandang keilmuan saja. Namun, lebih kompleks Jurgen Habermas akan menilainya dari beragam sudut pandang keilmuan untuk menemukan analisis yang komprehensif.

Realita tersebut sesuai dengan gagasan Jurgen Habermas (Habermas, 1992) yang menilai bahwa suatu disiplin ilmu tidak akan mampu berdiri sendiri, melainkan membutuhkan disiplin ilmu lain agar bisa menjawab kebutuhan zaman. Maka dari itu, sangat wajar jika ternyata dalam perkembangannya, ambang batas parlemen besarannya berubah-ubah karena melihat pada disiplin ilmu lain yang ikut menafsirkannya (Tata Strata, Hufron, 2019). Sehingga, gagasan Jurgen Habermas yang tidak melihat hukum sebagai ilmu yang berdiri sendiri (Tjahyadi, 2003), cukup relevan untuk dijadikan sebagai alat ukur dalam melihat sebuah norma hukum (Rahman, 2018). Meskipun demikian, perlu dibuat batasan agar kebutuhan untuk mengintegrasikan antara hukum dengan disiplin ilmu yang lain tidak melewati koridor fungsi dan tujuan hukum (Julyano \& Sulistyawan, 2019) itu sendiri. Dengan begitu hukum akan tetap menjadi ilmu yang memberikan kepastian, keadilan maupun kemanfaatan bagi manusia dan sekitarnya (Setiawan, 2017) (Kelsen, 1949) (Hanafi, 2016) (Soemarsono, 2017) (Shidiq, 2009).
Berdasarkan pembahasan tersebut diatas, dapat disimpulkan bahwa pembentukan norma ambang batas parlemen dalam pemilu berdasarkan perspektif teori kritis Jurgen Habermas adalah didasarkan pada unsur lain diluar hukum. Unsur tersebut termasuk unsur politis, ekonomi, HAM, hukum modern dan sebagainya, yang dipandang sebagai cara untuk mewujudkan sistem multi partai sederhana di tengah kebebasan membentuk dan mendirikan partai politik. Upaya tersebut membuktikan bahwa hukum tidak bisa berdiri sendiri dan harus berkolaborasi dengan disiplin ilmu yang lain. Meskipun demikian, perlu dibuat batasan agar kebutuhan untuk mengintegrasikan antara hukum dengan disiplin ilmu yang lain tidak melewati koridor fungsi dan tujuan hukum itu sendiri.

\section{DAFTAR PUSTAKA}

Adelina, A. (2018). RELEVANSI AMBANG BATAS PARLEMEN (PARLIAMENTARY THRESHOLD) DENGAN SISTEM PRESIDENSIAL DI INDONESIA (Universitas Islam Indonesia). Retrieved from https://dspace.uii.ac.id/handle/123456789/5874

Agustine, O. V. (2018). Keberlakuan Yurisprudensi pada Kewenangan Pengujian Undang-Undang dalam Putusan Mahkamah Konstitusi. Jurnal Konstitusi, 15(3), 642. https://doi.org/10.31078/jk1539

Al-Fatih, S. (2019). Akibat Hukum Regulasi tentang Threshold dalamPemilihan Umum Legislatif dan Pemilihan Presiden: Kajian Putusan Mahkamah Konstitusi Nomor 52/PUU-X/2012 dan Nomor 14/PUU-XI/2013. Jurnal Yudisial, 12(1), 17-38. https://doi.org/10.29123/jy.v12i1.258

Al-fatih, S., Safaat, M. A., \& Dahlan, M. (2014). Reformulasi Parliamentary Threshold Yang Berkeadilan Dalam Pemilu Legislatif Di Indonesia. Jurnal Hukum, 20. Retrieved from http://hukum.studentjournal.ub.ac.id/index.php/h ukum/article/view/1018/1007

Amri, R. (2008). HUKUM MODERN DAN

\section{PEMIKIRAN HUKUM DI INDONESIA.}

\section{PENUTUP}

Pembentukan Norma Ambang Batas Parlemen dalam Perspektif Teori Kritis Jurgen Habermas | 33 
Semarang.

Ansori, L. (2019). TELAAH TERHADAP PRESIDENTIAL THRESHOLD DALAM PEMILU SERENTAK 2019. Jurnal Yuridis, 4(1), 15-27. Retrieved from https://ejournal.upnvj.ac.id/index.php/Yuridis/art icle/view/124/99

Aulia, F., \& Al-Fatih, S. (2017). Perbandingan Sistem Hukum Common Law, Civil Law dan Islamic Law dalam Perspektif Sejarah dan Karakteristik Berpikir . Legality : Jurnal Ilmiah Hukum, 25(1), 98-113. Retrieved from http://202.52.52.22/index.php/legality/article/vie w/5993

Borradori, G. (2005). Filsafat dalam Masa Teror: Dialog dengan Jurgen Habermas dan Jacques Derrida. Jakarta: Kompas.

Chambers, S. (1996). Reasonable Democracy: Jürgen Habermas and the Politics of Discourse. London: Cornell University Press.

Effendi, A. (2017). Studi Komparatif Pengaturan Sistem Pemilihan Umum Anggota Dewan Perwakilan Rakyat Di Indonesia. Fiat Justisia, 10(2), 295-316. https://doi.org/10.25041/fiatjustisia.v10no2.746

Fahmi, K. (2017). Pemilihan Umum dalam Transisi Demokrasi: Kompilasi Catatan Atas Dinamika Pemilu dan Pilkada di Era Reformasi. Jakarta: Raja Grafindo Persada.

Faiz, P. M. (2018). Memperkuat Prinsip Pemilu yang Teratur, Bebas, dan Adil Melalui Pengujian Konstitusionalitas Undang-Undang. Jurnal Konstitusi, 14(3), 672. https://doi.org/10.31078/jk14310

Fakultas Hukum Universitas Gadjah Mada. (2020). Catatan Kritis Dan Rekomendasi Terhadap Ruu Cipta Kerja. Yogyakarta.

Fatih, S. Al. (2018). Implementasi Parliamentary Threshold Dalam Pemilihan Anggota Dprd Provinsi Dan Dprd Kabupaten/Kota. Ahkam: Jurnal Hukum Islam, 6(2). https://doi.org/10.21274/ahkam.2018.6.2.363388

Fatih, M. K. (2020). Terorisme dalam perspektif jurgen habermas. Al Furqan: Jurnal Imu Al Quran Dan Tafsir, 4(1), 31-47. Retrieved from http://ejournal.iaitabah.ac.id/index.php/Alfurqon/article/view/486/ 359

Habermas, J. (1992). Autonomy and Solidarity: Interviews with Jürgen Habermas (Revised Ed; P. Dews, Ed.). Retrieved from https://books.google.co.id/books?hl=id\&lr=\&id=

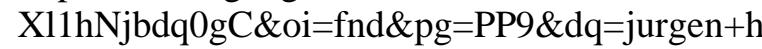
abermas\&ots $=$ QDuVAdof_J\&sig $=$ RCN7bI10Fb ghFfbQWmdXkDn3soQ\&redir_esc $=\mathrm{y} \# \mathrm{v}=$ onepa ge \&q=jurgen habermas $\& \mathrm{f}=$ false

Hadi, I. G. A. A., \& Brata, D. L. (2020). PENGARUH PENENTUAN PARLIAMENTARY THRESHOLD DALAM PEMILIHAN UMUM LEGISLATIF DAN SISTEM PRESIDENSIAL DI INDONESIA. Kertha Patrika, 42(1), 34-51. Retrieved from file:///Users/sholahuddinalfatih/Downloads/docu ment (4).pdf

Hanafi, M. (2016). Kedudukan Musyawarah dan Demokrasi di Indonesia. Jurnal Cita Hukum, 1(2). https://doi.org/10.15408/jch.v1i2.2657

Hardiman, F. B. (2009). Kritik Ideologi: Menyingkap Pertautan Pengetahuan dan Kepentingan Bersama Jurgen Habermas. Yogyakarta: Kanisius.

Hardiman, F. B. (2015). Seni Memahami Hermeneutik: Dari Schleiermacher sampai Derrida. Yogyakarta: Kanisius.

Harnay, S., \& Marciano, A. (2009). Posner, economics and the law: From "law and economics" to an economic analysis of law. Journal of the History of Economic Thought, 31(2), 215-232. https://doi.org/10.1017/S1053837209090208

Himawan, C. (1991). Pendekatan Ekonomi terhadap Hukum sebagai Sarana Pengembalian Wibawa Hukum. Hukum Dan Pembangunan, 21(5), 421445 .

Ilham Fajar Septian. (2019). Mengefektifkan Sistem Pemerintahan Dan Menyederhanakan Sistem Partai Politik: Belajar Kepada Pemilu Jerman. Majalah Hukum Nasional, 49(2), 57-85. https://doi.org/10.33331/mhn.v49i2.28 
Jati, W. R. (2013). Menuju Sistem Pemilu Dengan Ambang Batas Parlemen Yang Afirmatif. Jurnal Yudisial, (Vol 6, No 2 (2013): HAK DALAM KEMELUT HUKUM), 143-158. Retrieved from http://jurnal.komisiyudisial.go.id/index.php/jy/ar ticle/view/110

Julyano, M., \& Sulistyawan, A. Y. (2019).

Pemahaman Terhadap Asas Kepastian Hukum Melalui Konstruksi Penalaran Positivisme Hukum. Jurnal Crepido, 01(01), 13-22. https://doi.org/https://ejournal2.undip.ac.id/index .php/crepido/article/download/6325/3197

Kelsen, H. (1949). General theory of Law and State. [Teoría general del Derecho y del Estado].

Kholis, N. (2020). PARLIAMENTARY THRESHOLD AND POLITICAL RIGHTS LIMITATION. Journal of Law and Legal Reform, 1(3), 445-456. https://doi.org/https://doi.org/10.15294/jllr.v1i3. 36702

Kompas. (2019). Penetapan KPU: 9 Parpol Lolos Parlemen.

Lolong, W. (2017). Meneguhkan Ilmu-Ilmu Sosial Keindonesiaan. In Suharno, S. Rochmat, \& A. Wardhana (Eds.), Seminar Nasional dalam rangka Dies Natalis ke-53 UNY (pp. 1-371). Retrieved from https://www.researchgate.net/profile/Setia_Budh i4/publication/339202468_Meneguhkan_IlmuIlmu_Sosial_Keindonesiaan_Reviewer/links/5e4 3e869a6fdccd9659c16a0/Meneguhkan-IlmuIlmu-Sosial-Keindonesiaan-

Reviewer.pdf\#page $=89$

Lubis, A. Y. (2015). Pemikiran Kritis Kontemporer: Dari Teori Kritis, Culture Studies, Feminisme Postkolonial hingga Multikulturalisme. Jakarta: Rajawali Press.

Maftuh, M. A. (2020). PARLIAMENTARY THRESHOLD DALAM PEMILU SERENTAK TAHUN 2019 (Tinjauan Filosofis Asas Kedaulatan Rakyat) (IAIN Salatiga). Retrieved from http://erepository.perpus.iainsalatiga.ac.id/9775/

Malik, G. N. (2019). Biografi Pemikiran Politik:
Demokrasi Deliberatif Menurut Jurgen Habermas. Universitas Brawijaya.

Mellaz, A. (2012). Praktek Penerapan Keberlakuan 3,5 Persen Ambang Batas Parlemen Secara Nasional Undang-undang Nomor 8 tahun 2012 Tentang Pemilu. Retrieved from http://www.spdindonesia.com/wpcontent/uploads/2016/04/Ambang-Batas-TanpaBatas.pdf

Miller, K. (2002). Communications Theories: Perspectives, Processes, and Contexs. Boston: McGraw Hill Companies Inc.

Mouliza K.D Sweinstani. (2019). Formula Konversi Suara Saint Lague dan Dampaknya pada Sistem Kepartaian: Evaluasi Pemilu Serentak 2019. Jurnal Penelitian Politik (LIPI), 16(2), 111-124. Retrieved from http://ejournal.politik.lipi.go.id/index.php/jpp/art icle/view/812/549

Nielsen, K. (1985). Equality and Liberty: A Defense of Radical Egalitarianism. Retrieved from https://books.google.co.id/books?hl=id\&lr=\&id= YIDlkbqsc-

0C\&oi=fnd \&pg $=$ PP13\&dq=equality+liberty + da n+reciprocity\&ots $=M X i F m 2 I w 9 U \& s i g=y 6 p r P-$ nG9gw5mxV_EBkVffgFWD0\&redir_esc $=y$

Pamungkas, Y. (2014). Tinjauan Ambang Batas Perolehan Suara Berdasarkan UU No.8 Tahun 2012 tentang Pemilihan Anggota DPR, DPD dan DPRD terhadap UUD 1945. RechtsVinding, 3(8), 33-50.

https://doi.org/http://dx.doi.org/10.33331/rechtsv inding.v3i1.55

Peter Mahmud Marzuki. (2014). Penelitian Hukum. Jakarta: Kencana Prenada Media Group.

Peter Mahmud Marzuki. (2017). Penelitian Hukum: Edisi Revisi (Cetakan ke). Retrieved from https://books.google.co.id/books?id=CKZADwA AQBAJ\&printsec $=$ frontcover\&dq $=$ Marzuki, + Pet er+Mahmud,+(2014),+Penelitian+Hukum,+Ceta kan+ke-

9,+Jakarta:+Kencana+Media+Group.\&hl=id\&sa $=$ X\&ved=0ahUKEwiNlIjqlbTpAhXWWisKHW ktCXAQ6AEIMjAB\#v=onepage $\& \mathrm{q} \& \mathrm{f}=$ false 
Posner, R. (1985). An Economic Theory of The Criminal Law. Columbia Law Review, 85(6).

Putra, T. S. H. (2019). Pengaruh Ambang Batas Parlemen Terhadap Keberlangsungan Partai Politik Dalam Sistem Pemilu Di Indonesia (Universitas Muhammadiyah Sumatera Utara). Retrieved from https://core.ac.uk/download/pdf/225828768.pdf

Putri, E. K. (2018). URGENSI PENGATURAN KENAIKAN AMBANG BATAS BAGI PARTAI POLITIK ( Studi Undang- Undang Nomor 8 Tahun 2012 perbandingan Undang-Undang Nomor 7 tahun 2017). Universitas Islam Indonesia.

Putuhena, M. I. F. (2013). Politik Hukum Perundangundangan : Mempertega sReformasi Legislasi Yang Progresif. Rechtsvinding: Media Pembaharuan Hukum Nasional, 2(3), 375-395. Retrieved from http://ejurnal.peraturan.go.id/index.php/jli/article/downl oad $/ 334 / 218$

Rahman, M. S. (2018). Makna Filosofis Rechtstaat Dalam Konteks Kebijakan Pembangunan Hukum Di Indonesia. Meraja Journal, 1(2), 2621-458. Retrieved from https://merajajournal.merajamedia.com/jurnal/in dex.php/journal/index

Rawls, J. (1999). A Theory of Justice. Harvard University press.

Rustamaji, M. (2013). Menakar Pengawasan Pemberian Bantuan Hukum Dalam Pandangan Richard a Posner. Jurnal Rechts Vinding: Media Pembinaan Hukum Nasional, 2(1), 95. https://doi.org/10.33331/rechtsvinding.v2i1.84

Setiawan, A. (2017). Penalaran Hukum Yang Mampu Mewujudkan Tujuan Hukum Secara Proporsional. Jurnal Hukum Mimbar Justitia, 3(2), 204. https://doi.org/10.35194/jhmj.v3i2.257

Shidiq, G. (2009). TEORI MAQASHID ALSYARI'AH DALAM HUKUM ISLAM. Majalah Ilmiah Sultan Agung, 44(118). https://doi.org/10.1001/archneur.58.4.677

Sianipar, F. P. A. (2019). PENGARUH YURISPRUDENSI TERHADAP PRINSIP KEMERDEKAAN HAKIM. Tanjungpura Law,
3(1), 1-16.

https://doi.org/http://dx.doi.org/10.26418/tlj.v4i1 .41789

Simanjuntak, E. (2018). Peran Yurisprudensi dalam Sistem Hukum di Indonesia The Roles of Case Law in Indonesian Legal System. 16.

Sodiki, A. (2020). Yurisprudensi. Malang: DIH UB.

Soemarsono, M. (2017). Negara Hukum Indonesia Ditinjau Dari Sudut Teori Tujuan Negara. Jurnal Hukum \& Pembangunan2, 37(2), 300-322. https://doi.org/10.21143/jhp.vol37.no2.1480

Suheri, A. (2018). PENYELESAIAN TANAH SENGKETA ADAT MELALUI PROSES PERADILAN. Jurnal Jendela Hukum, 2(2), 3343. https://doi.org/10.24929/fh.v2i2.451

Suteki, \& Taufani, G. (2018). Metodologi Penelitian Hukum (Filasafat, Teori dan Praktik). Depok: Rajagrafindo Persada.

Tata Strata, Hufron, S. S. (2019). AMBANG BATAS PARLEMEN (PERLIAMENTARY THRESHOLD) DAN ASAS DEMOKRASI. Jurnal Akrab Juara, 4(5), 229-245. Retrieved from http://akrabjuara.com/index.php/akrabjuara/articl e/view/880/781

Taufiqulhadi, T. (2015). Relasi DPR, Partai Politik dan Konstituen. Jurnal Transvfrmative, 1(1), 19. Retrieved from https://transformative.ub.ac.id/index.php/jtr/artic le/view/112/155

Tjahyadi, S. (2003). TEORI KRITIS JÜRGEN HABERMAS: ASUMSI-ASUMSI DASAR MENUJU METODOLOGI KRITIK SOSIAL. Jurnal Filsafat, 34(2).

Umum, K. P. (2020). Partai Politik Peserta Pemilu 2019.

White, S. K. (1988). The Recent Work of Jürgen Habermas: Reason, Justice and Modernity. Melbourne: Cambridge University Press.

Wiratraman, H. P. (2018). Kebebasan Akademik, Neo-Feodalisme dan Penindasan HAM. In Hak Asasi Manusia: Politik, Hukum Dan Agama Di Indonesia (pp. 53-67). Jember: LKIS. 
Yazid, A. (2009). Hermeneutika Kritis Jurgen

Habermas. 1-13. Retrieved from

https://d1wqtxts1xzle7.cloudfront.net/60085784/

Hermeneutika_Kritis_Habermas_by_Abu_Yazid

_Al_Tantowi20190722-91064-

19cuxhw.pdf?1563848427=\&response-content-

disposition=inline \%3B+filename\%3DHermeneu

tika_Kritis_Habermas_by_Abu_Yazi.pdf\&Expir

es $=1607312599 \&$ Sig 